\title{
Is physiology of coronary blood flow different in men and women?
}

\author{
Raffaele Giubbini, $M D{ }^{a}$ and Domenico Albano, $M D^{a}$ \\ a Nuclear Medicine, University of Brescia, Brescia, Italy
}

Received May 25, 2018; accepted May 25, 2018

doi:10.1007/s12350-018-1346-0

\section{See related article, pp. 159-170}

The study in this issue of the Journal analyzed the blood pressure (BP) and heart rate responses after adenosine infusion in a large group of patients undergoing vasodilators stress testing. ${ }^{1}$. The hypothesis tested is that there is a gender- and age-dependent responses to adenosine that can identify high-risk patients with a worse prognosis especially in young women.

The authors cite several prior studies. Izadnegahdar et al. ${ }^{2}$ analyzed sex differences in acute myocardial infarction (AMI) hospitalization and early mortality rates in young adults. They observed that the overall, age-standardized AMI rates as well 30-day mortality rates declined similarly in men and women from 2000 to 2009, although there was an excess 30-day mortality in women less than 55 years of age compared to younger men. Wilmot et al. ${ }^{3}$ estimated the annual percentage change in mortality between 1979 and 2011 in patients less than 55 years of age. The estimated annual percentage change in mortality was $-2.8 \%$ in men and $-1.9 \%$ in women. However, the cardiac deaths were 3.5 times higher in men.

In France Gabet et al. ${ }^{4}$ observed that in 2014, more men than women were hospitalized for acute coronary syndromes (ACS) $(36,480$ women or $32.2 \%$ vs. 76,927 men or $67.8 \%$ ). Mean age at hospital admission was higher in women (73.8 years) than in men (65.8 years). The proportion of patients aged $<65$ years was $25.2 \%$ among women and $46.7 \%$ among men. In-hospital mortality was higher in women than in men $(6.4 \%$ vs. $3.4 \%)$. The age-standardized rate of patients hospitalized

Reprint requests: Raffaele Giubbini, MD, Nuclear Medicine, University of Brescia, Brescia, Italy; giubbini@med.unibs.it

J Nucl Cardiol 2020;27:171-2.

$1071-3581 / \$ 34.00$

Copyright (C) 2018 American Society of Nuclear Cardiology. for ACS was approximatively three times lower in women compared to men.

Otaki et al. ${ }^{5}$ examined the relationship between cardiovascular risk factors, prevalence, and severity of coronary atherosclerosis in a large (1635 individuals), prospective, multinational registry of consecutive young (less than 45 years) individuals undergoing coronary computerized tomographic angiography. They found by multivariable analysis that male sex was the strongest predictor of both calcified and non-calcified plaques and that family history of coronary artery disease (CAD) was the strongest predictor for obstructive CAD. Therefore, it may be questionable the assumption that in CAD patients, female gender represents a negative prognostic risk factor. On the other hand, there is no clear explanation about the mechanisms of the high prevalence of sudden cardiac death in women without obstructive CAD. Endothelial dysfunction or coronary microvascular dysfunction could be suggested as mechanisms that induce ischemia in women with non-obstructive CAD. ${ }^{6}$

The PET prognosis multicenter registry ${ }^{7}$ showed that the addition of stress myocardial perfusion $\mathrm{Rb}-82$ PET data provided improvement in risk re-classification in both women $(n=2904)$ and men $(n=3133)$. For both men and women, there was a direct proportional relationship between increasingly abnormal stress perfusion score and age. For the oldest group of women with a $>10 \%$ perfusion defect, the annual adjusted CAD mortality was comparable to that of the corresponding group of men. Conversely, the event rate was very low in women $<50$ years of age and the percentage of abnormal myocardium at vasodilator stress testing (adenosine or dipyridamole) was of borderline significance.

In the paper of Gebhard et al heart rate, systolic and mean BP significantly increased during adenosine infusion and the increase was significantly higher in women compared to men. Patients $\leq 55$ years had a higher heart rate reserve (peak heart rate during adenosine infusion minus baseline heart rate/baseline heart rate $\times 100$ ) as 
compared to patients $>55$ years. The increase in heart rate is expected after vasodilator infusion whereas an increase in $\mathrm{BP}$ is an unexpected finding.

In the ADVANCE MPI trial, systolic BP decreased by $14 \pm 13 \mathrm{~mm} \mathrm{Hg}$ with adenosine and by $13 \pm 14 \mathrm{~mm}$ $\mathrm{Hg}$ with regadenoson, while diastolic BP decreased by $10 \pm 8 \mathrm{~mm} \mathrm{Hg}$ with both agents. ${ }^{8}$

Adenosine affects the cardiovascular system by different actions mediated by four 4 subtypes of adenosine receptors $\left(A_{1}, A_{2 \mathrm{~A}}, A_{2 \mathrm{~B}}, A_{3}\right) . A_{1}$ receptors affect the activity of sinus node and atrioventricular node inducing bradycardia and AV block. Activation of $A_{2 \mathrm{~A}}$ and $A_{2 \mathrm{~B}}$ produces coronary and peripheral vasodilation causing a decrease in BP. Further, a direct $A_{2 \mathrm{~A}}$ receptormediated activation of sympathetic afferents in the sinoatrial node level increases heart rate. For this reason, the injection of regadenoson that activates only $A_{2 \mathrm{~A}}$ receptors is systematically associated with a significant increase in heart rate. ${ }^{9}$ An increase in BP could be due to increases in cardiac output, heart rate, and cardiac contractility and/or an increase of sympathetic driven peripheral resistance (likely due to anxiety). Therefore, different physiological mechanisms could compensate for the peripheral vasodilation induced by $A_{2 \mathrm{~A}}$ receptors stimulation to prevent a decrease in BP. Women have smaller coronary arteries, higher coronary blood flow and consequently high endothelial shear stress. ${ }^{10}$ Reduced global quantitative stress blood flow or coronary flow reserve defined as microvascular dysfunction can be detected by quantitative PET with perfusion tracer in women; ${ }^{11}$ however, Gebhard et al. found a significant association between heart rate and systolic BP increase and stress-induced perfusion defects by SPECT (using semiquantitative visual analysis which is not ideal for evaluating microvascular dysfunction). Diffuse epicardial coronary atherosclerosis in the absence of flow-limiting stenosis in association to microvascular dysfunction could induce regional flow maldistribution $^{12}$ detectable by SPECT, but likely underestimate the degree of abnormality. A prospective study with quantitative PET in men and women less than 55 years is needed to confirm these preliminary findings.

\section{References}

1. Gebhard C, Messerli M, Lohmann C, Treyer V, Bengs S, Benz D, et al. Sex-and age-differences in the association of heart rate responses to adenosine and myocardial ischemia in patients undergoing myocardial perfusion imaging. J Nucl Cardiol 2018.

2. Izadnegahdar M, Singer J, Lee MK, Gao M, Thompson CR, et al. Do younger women fare worse? Sex differences in acute myocardial infarction hospitalization and early mortality rates over ten years. J Womens Health (Larchmt) 2014;23:10-7.

3. Wilmot KA, O'Flaherty M, Capewell S, Ford ES, Vaccarino V. Coronary heart disease mortality declines in the united states from 1979 through 2011: Evidence for stagnation in young adults, Especially women. Circulation 2015;132(11):997-1002.

4. Gabet A, Danchin N, Juilliere Y, Olie V. Acute coronary syndrome in women: Rising hospitalizations in middle-aged French women, 2004-2014. Eur Heart J 2017;38:1060-5.

5. Otaki Y, Gransar H, Cheng VY, Dey D, Labounty T, Lin FY, et al. Gender differences in the prevalence, severity, and composition of coronaryartery disease in the young: A study of 1635 individuals undergoing coronary CTangiography from the prospective, multinational confirm registry. Eur Heart J Cardiovasc Imaging. 2015.

6. Mehta PK, Johnson BD, Kenkre TS, Eteiba W, Sharaf B, Pepine $\mathrm{CJ}$, et al. Sudden cardiac death in women with suspected ischemic heart disease, preserved ejection fraction, and no obstructive coronary artery disease: A report from the women's ischemia syndrome evaluation study. J Am Heart Assoc 2017;6(8):e005501.

7. Kay J, Dorbala S, Goyal A, Fazel R, Di Carli MF, Einstein AJ, et al. Influence of sex on risk stratification with stress myocardial perfusion Rb-82 positron emission tomography: Results from the PET (positron emission tomography) prognosis multicenter registry. J Am Coll Cardiol 2013;62(20):1866-76.

8. Iskandrian AE, Bateman TM, Belardinelli L, Blackburn B, Cerqueira MD, Hendel RC, et al. Adenosine versus regadenoson comparative evaluation in myocardial perfusion imaging: Results of the ADVANCE phase 3 multicenter international trial. J Nucl Cardiol 2007;14:645-58.

9. Hage FG, Heo J, Franks B, Belardinelli L, Blackburn B, Wang W, et al. Differences in heart rate response to adenosine and regadenoson in patients with and without diabetes mellitus. Am Heart J 2009;157:771-6.

10. Patel MB, Bui LP, Kirkeeide RL, Gould KL. Imaging microvascular dysfunction and mechanisms for female-male differences in CAD. JACC Cardiovasc Imaging 2016;9:465-82.

11. Murthy VL, Naya M, Taqueti VR, Foster CR, Gaber M, Hainer J, et al. Effects of sex on coronary microvascular dysfunction and cardiac outcomes. Circulation 2014;129:2518-27.

12. Lee BK, Lim HS, Fearon WF, Yong AS, Yamada R, Tanaka S, et al. Invasive evaluation of patients with angina in the absence of obstructive coronary artery disease. Circulation 2015;131:1054-60.

\section{Disclosure}

Raffaele Giubbini and Domenico Albano declare that there is no conflict of interest to disclose. 